\title{
Heterogeneous freezing of droplets with immersed mineral dust particles - measurements and parameterization
}

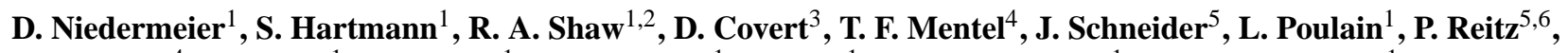 \\ C. Spindler ${ }^{4}$, T. Clauss ${ }^{1}$, A. Kiselev ${ }^{1}$, E. Hallbauer ${ }^{1}$, H. Wex ${ }^{1}$, K. Mildenberger ${ }^{1}$, and F. Stratmann ${ }^{1}$ \\ ${ }^{1}$ Leibniz Institute for Tropospheric Research, 04318 Leipzig, Germany \\ ${ }^{2}$ Department of Physics, Michigan Technological University, Houghton, MI 49931, USA \\ ${ }^{3}$ Joint Institute for the Study of the Atmosphere and Ocean, University of Washington, Seattle, WA 98195, USA \\ ${ }^{4}$ ICG-2: Troposphere, Research Center Jülich, 52425 Jülich, Germany \\ ${ }^{5}$ Particle Chemistry Department, Max Planck Institute for Chemistry, 55128 Mainz, Germany \\ ${ }^{6}$ Institute for Atmospheric Physics, Johannes Gutenberg University, 55099 Mainz, Germany
}

Received: 16 July 2009 - Published in Atmos. Chem. Phys. Discuss.: 24 July 2009

Revised: 26 March 2010 - Accepted: 9 April 2010 - Published: 19 April 2010

\begin{abstract}
During the measurement campaign FROST (FReezing Of duST), LACIS (Leipzig Aerosol Cloud Interaction Simulator) was used to investigate the immersion freezing behavior of size selected, coated and uncoated Arizona Test Dust (ATD) particles with a mobility diameter of $300 \mathrm{~nm}$. Particles were coated with succinic acid $\left(\mathrm{C}_{4} \mathrm{H}_{6} \mathrm{O}_{4}\right)$, sulfuric acid $\left(\mathrm{H}_{2} \mathrm{SO}_{4}\right)$ and ammonium sulfate $\left(\left(\mathrm{NH}_{4}\right)_{2} \mathrm{SO}_{4}\right)$. Ice fractions at mixed-phase cloud temperatures ranging from $233.15 \mathrm{~K}$ to $239.15 \mathrm{~K}( \pm 0.60 \mathrm{~K})$ were determined for all types of particles. In this temperature range, pure ATD particles and those coated with $\mathrm{C}_{4} \mathrm{H}_{6} \mathrm{O}_{4}$ or small amounts of $\mathrm{H}_{2} \mathrm{SO}_{4}$ were found to be the most efficient ice nuclei (IN). ATD particles coated with $\left(\mathrm{NH}_{4}\right)_{2} \mathrm{SO}_{4}$ were the most inefficient IN. Since the supercooled droplets were highly diluted before freezing occurred, a freezing point suppression due to the soluble material on the particles (and therefore in the droplets) cannot explain this observation. Therefore, it is reasonable to assume that the coatings lead to particle surface alterations which cause the differences in the IN abilities. Two different theoretical approaches based on the stochastic and the singular hypotheses were applied to clarify and parameterize the freezing behavior of the particles investigated. Both approaches describe the experimentally determined results, yielding parameters that can subsequently be used to compare our results to those from other studies. How-
\end{abstract}

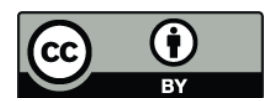

Correspondence to: D. Niedermeier (niederm@tropos.de) ever, we cannot clarify at the current state which of the two approaches correctly describes the investigated immersion freezing process. But both approaches confirm the assumption that the coatings lead to particle surface modifications lowering the nucleation efficiency. The stochastic approach interprets the reduction in nucleation rate from coating as primarily due to an increase in the thermodynamic barrier for ice formation (i.e., changes in interfacial free energies). The singular approach interprets the reduction as resulting from a reduced surface density of active sites.

\section{Introduction}

Among other factors, ice containing clouds, such as cirrus and mixed-phase clouds have an impact on Earth's radiative balance by scattering and absorbing solar and terrestrial radiation (Hung et al., 2003; Zuberi et al., 2002) with ice formation processes strongly influencing cloud radiative properties (DeMott et al., 2003b). Additionally, the formation of ice crystals affects cloud dynamics and chemical processes in clouds and is one of the most effective pathways to form precipitation in the midlatitudes. Therefore, ice particles affect cloud lifetime (Lohmann, 2006).

Ice formation in the atmosphere may happen via both homogeneous and heterogeneous nucleation, the latter being induced by a foreign insoluble core called an ice nucleus (IN) (Cantrell and Heymsfield, 2005). Four different

Published by Copernicus Publications on behalf of the European Geosciences Union. 
heterogeneous ice nucleation modes are distinguished in the literature: Deposition nucleation mode as well as condensation, immersion and contact freezing modes (e.g., Pruppacher and Klett, 1997). In the deposition mode, ice deposits on the particle directly from the vapor phase, without an intermediate liquid phase, i.e., usually the particle environment is super-saturated with respect to ice only. Condensation freezing occurs when the particle acts as cloud condensation nucleus $(\mathrm{CCN})$ at a certain temperature below the melting point of ice and the freezing process takes place at the same temperature. For immersion freezing, Pruppacher and Klett (1997) stated that the particle becomes immersed into a droplet above the melting point of ice and freezing is initiated when the temperature of this droplet becomes sufficiently low. But evidence exists that particles act as $\mathrm{CCN}$ below $273.15 \mathrm{~K}$, and then induce immersion freezing due to further cooling (Megahed, 2007). Finally, freezing can also be initiated by an insoluble particle which penetrates the surface of a supercooled liquid droplet from the outside. This so-called contact freezing apparently could also occur if the particle penetrates the droplet surface from the inside out, due to particle movement or an evaporation process (Shaw et al., 2005; Durant and Shaw, 2005).

The relative importance of the freezing modes in the atmosphere is not known, and in general our understanding of the physical and chemical processes underlying heterogeneous ice formation is limited. E.g., until now, it is still unclear if heterogeneous ice nucleation is a stochastic process (stochastic hypothesis) or if nucleation occurs on specific sites at characteristic temperatures (singular hypothesis). In recent literature (e.g., Archuleta et al., 2005; Connolly et al., 2009; Marcolli et al., 2007; Vali, 1994) both hypotheses were used to evaluate and parameterize heterogenous ice nucleation measurements but a definite answer is still missing. Therefore, more scientific work, both theoretical and experimental, is necessary to elucidate the fundamental physical mechanisms, as well as to develop adequate parameterizations that are required for cloud models (Cantrell and Heymsfield, 2005; Kärcher and Lohmann, 2003).

Various atmospheric observations of droplet freezing through heterogeneous ice nucleation show that insoluble substances, especially mineral dust particles, serve effectively as IN in the atmosphere (Cziczo et al., 2004; DeMott et al., 2003a,b; Richardson et al., 2007; Sassen et al., 2003). As a result mineral dust particles indirectly influence cloud properties, precipitation, and therefore Earth's climate (DeMott et al., 2003a,b; Zuberi et al., 2002). Mineral dust particles originate from desert regions like the Sahara and the Gobi and can be lifted into the free troposphere during storm events. Subsequent to lifting, the dust particles can be transported over large distances (Prospero, 1999; Sassen et al., 2003; DeMott et al., 2003a) and undergo aging processes, e.g., through coatings with sulfates and other electrolytes (Zuberi et al., 2002). As a result, IN ability may change.
In the laboratory several investigations concerning the IN ability of different kinds of mineral dust particles (with and without coatings) were carried out utilizing a variety of measurement methods and thermodynamic conditions (e.g., Archuleta et al., 2005; Cziczo et al., 2009; Field et al., 2006; Knopf and Koop, 2006; Marcolli et al., 2007; Möhler et al., 2006; Zobrist et al., 2008). As a consequence, our understanding of the influence of certain particles, especially mineral dusts, on different freezing modes has improved. Some of these experiments show that coatings lower the IN efficiency of dust particles. But the question remains whether the coatings tend to only cover the particle surface or also lead to surface modifications. The studies also had limitations, some of which we are addressing in this work. In some cases only threshold temperatures/ice saturation ratios for freezing onset ( $1 \%$ of the particles activated as IN) are given (Archuleta et al., 2005; Field et al., 2006; Möhler et al., 2006). In other cases the IN ability of particles with broad size distributions was investigated (Field et al., 2006; Knopf and Koop, 2006; Marcolli et al., 2007; Möhler et al., 2006; Zobrist et al., 2008) providing little information about the influence of particle size on freezing. Taken together, the studies are partly difficult to compare, and even when certain results can be compared they are not entirely consistent. For example measurements concerning deposition nucleation of mineral dust particles performed by Archuleta et al. (2005) (Asian Dust, $\mathrm{Al}_{2} \mathrm{O}_{3}$ and $\mathrm{Fe}_{2} \mathrm{O}_{3}$ particles), Knopf and Koop (2006) (Arizona Test Dust (ATD) particles) and Möhler et al. (2006) (ATD particles) give an inconsistent picture. For temperatures at about $240 \mathrm{~K}$, Möhler et al. (2006) and Knopf and Koop (2006) determined similar ice onset supersaturations. For lower temperatures, Möhler et al. (2006) observed ice onsets at lower ice supersaturations compared to ice onsets determined by Knopf and Koop (2006) and Archuleta et al. (2005). The explanations given by Knopf and Koop (2006) can partly resolve the observed difference but the question remains why the results are similar for higher temperatures and differ for temperatures below $235 \mathrm{~K}$.

During the measurement campaign FROST (FReezing Of duST) which took place in April 2008, the laminar flow diffusion chamber LACIS (Leipzig Aerosol Cloud Interaction Simulator) (Stratmann et al., 2004) was applied to investigate the ability of mineral dust particles to act as IN. LACIS allows the investigation of immersion freezing, such that the influence of size selected monodisperse particles on the freezing behavior of droplets can be measured, with only one particle being immersed in each droplet. LACIS can be used to determine ice fractions as function of temperature.

In the following, we first describe the fundamentals of the two above mentioned theoretical approaches, i.e., the stochastic and the singular approach. We relate both approaches to ice fractions, the parameter that resulted from our LACIS measurements. These measurements are subsequently described. Size segregated ATD particles were used for the freezing experiments. To simulate aging 
processes, the ATD particles were coated with various substances such as ammonium sulfate $\left(\left(\mathrm{NH}_{4}\right)_{2} \mathrm{SO}_{4}\right)$, sulfuric acid $\left(\mathrm{H}_{2} \mathrm{SO}_{4}\right.$, two different coating temperatures) and succinic acid $\left(\mathrm{C}_{4} \mathrm{H}_{6} \mathrm{O}_{4}\right)$. For ice fractions derived from FROST measurements, the stochastic and the singular approach were applied separately to clarify and parameterize the freezing behavior of the different kinds of particles. For the stochastic approach, we derive ice nucleation rate coefficients which are not instrument specific and therefore generally comparable. For the singular approach, the determined ice fractions can be already compared to other studies because for this approach freezing is assumed to be time-independent.

\section{Theoretical approach for data interpretation and parameterization}

\subsection{Stochastic approach}

To begin with, we consider the stochastic nature of the freezing process, based on a simplified expression obtained from classical nucleation theory (CNT). The purpose is to quantify the immersion freezing behavior of the particles investigated, and we reason that its use is justified for an ice nucleus population with uniform properties.

CNT is far from serving as an accurate description of nucleation processes, on the one side due to uncertainties in the required parameters (e.g., different parameterizations exist for e.g., the vapor pressures of supercooled water and ice as well as the interfacial free energy), and on the other side due to simplified assumptions underlying the theory itself (e.g., it is assumed that the interfacial free energy of clusters consisting of a small number of water molecules is the same as the free energy of the bulk liquid). Nevertheless, it may be used in a phenomenological way to interpret observations (Shaw et al., 2005). For example, CNT provides a feasible method for parameterizing homogenous and heterogeneous ice nucleation as functions of temperature.

For heterogenous freezing the nucleation rate coefficient $j_{\text {het }}$ can be expressed as (Pruppacher and Klett, 1997):

$j_{\text {het }}(T)=\frac{k T}{h} \exp \left[-\frac{\triangle F(T)}{k T}\right] \times n_{\mathrm{s}} \exp \left[-\frac{\triangle G_{\text {het }}(T)}{k T}\right]$

where $h$ and $k$ are the Planck and Boltzmann constants, respectively. $T$ represents the absolute temperature and $n_{\mathrm{s}}$ is the number density of water molecules at the ice nucleus/water interface (about $10^{19} \mathrm{~m}^{-2}$ ). $\triangle F(T)$ is the activation energy for diffusion of water molecules crossing the liquid water/ice boundary. $\triangle G_{\text {het }}(T)$ represents the Gibbs free energy for critical ice embryo formation in the presence of an IN. In general, the first term in Eq. (1) essentially describes the flux of water molecules to the embryonic ice particles (kinetic term) and the second term represents the equilibrium number of critical embryos in the liquid phase (thermodynamic term) (e.g., Shaw et al., 2005).
Using the simplest spherical cap geometry for the ice germ, the Gibbs free energy $\triangle G_{\text {het }}(T)$ can be written as (Seinfeld and Pandis, 1998):

$\triangle G_{\text {het }}(T)=\frac{16 \pi v_{\mathrm{i}}^{2}(T) \sigma_{\mathrm{w}, \mathrm{i}}{ }^{3}(T)}{3\left(k T \ln \frac{p_{\mathrm{w}}(T)}{p_{\mathrm{i}}(T)}\right)^{2}} f_{\text {het }}$

with $v_{\mathrm{i}}(T)$ being the volume per water molecule in the ice phase, $\sigma_{\mathrm{w}, \mathrm{i}}(T)$ being the interfacial free energy between liquid water and the ice embryo. $f_{\text {het }}$ represents the reduction of the energy barrier in consequence of the IN presence. $p_{\mathrm{w}}(T)$ and $p_{\mathrm{i}}(T)$ are the vapor pressures of supercooled liquid water and ice, respectively. The strongest temperature dependencies in Eq. (2) are in the vapor pressures and the surface free energy, so we proceed by focusing on those two terms. The ratio $p_{\mathrm{w}}(T) / p_{\mathrm{i}}(T)$, representing the saturation ratio, can be written as (e.g., Rogers and Yau, 1996):

$\frac{p_{\mathrm{w}}(T)}{p_{\mathrm{i}}(T)}=\exp \left(\frac{l_{\mathrm{f}}}{k T} \frac{T_{\mathrm{s}}}{T_{\circ}}\right)$

where $l_{\mathrm{f}}$ is the molecular latent heat of fusion, $T_{\circ}$ is the melting point temperature, and $T_{\mathrm{S}} \equiv T_{\circ}-T$ is the supercooling temperature. From the existing expressions describing the vapor pressures of supercooled water and ice, we chose this expression because it captures the essential temperature dependence in a simple way, and it is expressed as a function of $T_{\mathrm{S}}$. Using more accurate expressions belies the fact that there are greater uncertainties embedded in other parameters.

The surface free energy $\sigma_{\mathrm{w}, \mathrm{i}}(T)$ can also be expressed in terms of $T_{\mathrm{s}}$, which we obtain by adapting the expression of Zobrist et al. (2007) $\left(\sigma_{\mathrm{w}, \mathrm{i}}(T)=\tilde{\sigma}_{\mathrm{w}, \mathrm{i}}\left[1-\left(T_{\mathrm{S}} / C_{1}\right)\right]\right.$, valid for $230 \mathrm{~K} \leq T \leq 244 \mathrm{~K}$ ) with $\tilde{\sigma}_{\mathrm{w}, \mathrm{i}}=0.0412 \mathrm{~J} \mathrm{~m}^{-2}$ and $C_{1}=82.4 \mathrm{~K}$. For $\Delta F$ and $v_{\text {i }}$ parameterizations also exist (Zobrist et al., 2007) but given that the absolute temperature $T$ does not change significantly (FROST measurements were performed within a temperature range $<10 \mathrm{~K}$ ), we can reasonably take $\triangle F, l_{\mathrm{f}}$ and $v_{\mathrm{i}}$ as constants for the investigated temperature range. The temperature dependence of these parameters is small in the interval from $233.15 \mathrm{~K}$ to $243.15 \mathrm{~K}$, changing by about $8 \%, 10 \%$ and $0.1 \%$, respectively. Using Eqs. (2) and (3) and the stated assumptions, $j_{\text {het }}$ can be written as:

$j_{\text {het }}\left(T_{\mathrm{s}}\right)=a^{\prime} \times \exp \left[-\frac{C_{2}\left(1-\frac{T_{\mathrm{s}}}{C_{1}}\right)^{3}}{T_{\mathrm{s}}^{2}} f_{\text {het }}\right]$

with $a^{\prime}=\frac{k T n_{\mathrm{s}}}{h} \exp \left(\frac{-\triangle F}{k T}\right)$ and $C_{2}=\frac{16 \pi v_{\mathrm{i}}^{2} T_{\mathrm{o}}^{2} \tilde{\sigma}_{\mathrm{w}, \mathrm{i}}^{3}}{3 k T l_{\mathrm{f}}^{2}}$.

In the following, this CNT based nucleation rate coefficient will be connected to the ice fraction (i.e., the number of frozen droplets $N_{\mathrm{f}}$ divided by the total number of particles, $N_{0}$ ), as measured with LACIS during the FROST campaign. Here, we take advantage of the fact that inside LACIS only one IN is present per droplet. Because of the narrow particle size distribution of the ATD particles (see Wex et al., 2010) 
and the lack of information on precise properties of single particles, we make the simplified assumption that the investigated particles feature a similar size, a similar surface and similar surface properties. In addition, the nucleation event in an individual droplet is assumed to be independent of the nucleation event in other droplets of the population and the ice formation is the consequence of only one nucleation event per droplet (Pruppacher and Klett, 1997). The last assumption is reasonable because of the fast crystallization rate of ice. Hence, it is likely that the first critical embryo, formed on the particle surface, initiates the freezing before further embryos can be formed.

Under these assumptions and considering the axial temperature profile inside LACIS (see Fig. 3) the temporal change of the number of unfrozen droplets $N_{\mathrm{u}}$ can be written as:

$$
\frac{d N_{\mathrm{u}}}{d t^{\prime}}=-N_{\mathrm{u}} s_{\mathrm{p}} j_{\mathrm{het}}\left(T_{\mathrm{S}}\left(t^{\prime}\right)\right)
$$

with $d N_{\mathrm{u}}=-d N_{\mathrm{f}}$. Here, $s_{\mathrm{p}}$ is the particle surface area and $N_{\mathrm{f}}$ is the number of frozen particles. Integrating Eq. (5) yields:

$$
f_{\text {ice }}=\frac{N_{\mathrm{f}}}{N_{0}}=1-\exp \left(-s_{\mathrm{p}} \int_{0}^{t} j_{\text {het }}\left(T_{\mathrm{s}}\left(t^{\prime}\right)\right) d t^{\prime}\right)
$$

where $f_{\text {ice }}$ represents the ice fraction, or the probability of freezing (Shaw et al., 2005) and $t$ is the nucleation time.

Assuming that the major part of ice is formed in the region inside LACIS where the supercooling temperature is highest and almost constant (see the temperature profile inside LACIS in Fig. 3) Eq. (6) simplifies to:

$$
f_{\text {ice }}=1-\exp \left(-s_{\mathrm{p}} j_{\text {het }}\left(T_{\mathrm{s}}\right) t\right) \text {. }
$$

Finally, Eq. (4) can be inserted into Eq. (7) resulting in:

$$
f_{\text {ice }}=1-\exp \left(-a \times \exp \left(-\frac{C_{2}\left(1-\frac{T_{\mathrm{s}}}{C_{1}}\right)^{3}}{T_{\mathrm{s}}^{2}} f_{\text {het }}\right) t\right) \text {. }
$$

Here, $a=a^{\prime} s_{\mathrm{p}}$ and $f_{\text {het }}$ are adjustable parameters for matching theoretically and experimentally determined ice fractions. Parameter $a$ includes information about the total particle surface area and kinetic effects, whereas $f_{\text {het }}$ contains information about surface properties and thermodynamic effects. It should be noted that the parameterization developed here can be used to derive nucleation rates which are not instrument specific and therefore generally comparable.

\subsection{Singular approach}

The singular hypothesis assumes that in a liquid droplet containing an immersed insoluble particle, ice germs form on specific sites on the particle surface at a characteristic temperature $T_{\mathrm{c}}$ (Langham and Mason, 1958; Pruppacher and Klett, 1997; Vali, 1994). These specific sites, also called active sites, are considered as preferred sites, characterized by a size comparable to that of a critical ice embryo and the free energy of the particle-ice interface being minimal (Fletcher, 1969; Vali, 2008). The active site with the highest characteristic temperature determines the freezing temperature of the droplet. Being cooled to $T_{\mathrm{c}}$, a supercooled water droplet population including IN with these active sites will freeze instantaneously. If the temperature is constant afterwards, no additional nucleation events will occur, i.e., the freezing process is time-independent.

For this approximation, one can define the number of sites per surface area $n_{\mathrm{S}}\left(T_{\min }\right)$ which become active between temperature $T_{\circ}=0{ }^{\circ} \mathrm{C}$ and $T_{\min }$, where $T_{\min }$ is the minimum temperature reached during one experiment. $n_{\mathrm{s}}\left(T_{\min }\right)$ is called ice-active surface site density and can be expressed as (Connolly et al., 2009):

$n_{\mathrm{S}}\left(T_{\min }\right)=-\int_{T_{\circ}}^{T_{\min }} k(T) d T$.

The parameter $k(T)$ is the density of surface sites that become ice-active as the temperature is lowered by $d T$ (Connolly et al., 2009).

The change of the number of unfrozen droplets per temperature interval can be expressed as:

$\frac{d N_{\mathrm{u}}}{d T}=-N_{\mathrm{u}} s_{\mathrm{p}} k(T)$

with $d N_{\mathrm{u}}=-d N_{\mathrm{f}}$. Again, $s_{\mathrm{p}}$ is the particle surface area, and $N_{\mathrm{u}}$ and $N_{\mathrm{f}}$ are the number of unfrozen and frozen particles, respectively. Integrating Eq. (10) from the total number $N_{0}$ at $T_{\circ}$ to $N_{\mathrm{u}}$ at $T_{\min }$ and considering Eq. (9) yields:

$$
f_{\text {ice }}=\frac{N_{\mathrm{f}}}{N_{0}}=1-\exp \left(-s_{\mathrm{p}} n_{\mathrm{s}}\left(T_{\min }\right)\right) \text {. }
$$

During FROST experiments ice fractions were determined from which $n_{\mathrm{s}}\left(T_{\min }\right)$ can be derived assuming that for one particle sample (e.g., pure ATD particles) $n_{\mathrm{s}}\left(T_{\min }\right)$ is constant for fixed $T_{\min }$. This assumption is justified because of the narrow particle size distribution of the ATD particles, i.e., the particles should feature a similar size, a similar surface and similar surface properties, i.e., similar active sites.

Unlike the stochastic approach, which is based on classical nucleation theory, the singular approach currently has no theoretical foundation, and therefore the density of active sites is a purely empirical quantity. Essentially, a functional form is chosen that results in a satisfactory temperature dependence consistent with the observations. In spite of this empiricism, if the underlying assumption of the existence of active sites is accepted, then the fit provides an estimate of the temperature-dependent density of sites that can be compared to that derived in other, independent studies.

For parameterizing $n_{\mathrm{s}}(T)$, a polynomial expression is used as suggested in Connolly et al. (2009):

$$
n_{\mathrm{s}}(T)=\left\{\begin{array}{rll}
\alpha_{1}\left(T+\alpha_{2}\right)^{2} & : & T<-\alpha_{2} \\
0 & : & T \geq-\alpha_{2},
\end{array}\right.
$$


Here $\alpha_{1}$ and $\alpha_{2}$ are adjustable parameters for matching theoretically and experimentally determined ice fractions. The parameter $-\alpha_{2}$ determines the highest characteristic temperature for the corresponding particles sample. Note that the temperature in this polynomial fit has to be given in ${ }^{\circ} \mathrm{C}$. For details please refer to Connolly et al. (2009).

\section{Experimental procedure}

\subsection{Particle generation and size selection}

Figure 1 shows the particle generation setup. The ATD particles (ISO 12103-1, A1 Ultrafine Test Dust, Powder Technology Inc., Burnsville, Minnesota, USA) were dispersed by means of a fluidized bed generator (TSI 3400A, TSI Inc., St. Paul, Minnesota, USA). As a result of friction in the fluidized bed the particles are multiply charged and a self-built unipolar corona discharger is used to discharge them partially. Care was taken to assure that the corona discharger did not change the IN ability of the examined particles by comparing measurements as they were regularly done (with the discharger) to some done without it. No changes were observed.

Particles with an aerodynamic diameter larger than $560 \mathrm{~nm}$ were removed from the aerosol flow by means of a MicroOrifice Uniform-Deposit Impactor (MOUDI Model 100R, MSP Corporation, Shoreview, Michigan, USA). The remaining particles were charged electrically utilizing a Krypton 85 neutralizer. Coatings were applied in vapor diffusion tubes, heated to suited temperatures. Figure 1 depicts a sketch of the setup, showing three different tubes through either of which the particles could be led. Tube (A) is a bypass section where the uncoated particles were passed through. The second tube (B) contained a small "boat" filled with $\mathrm{C}_{4} \mathrm{H}_{6} \mathrm{O}_{4}$. This tube was heated up to $80^{\circ} \mathrm{C}$ using a heating tape. The temperature stability of this tape was about $\pm 2 \mathrm{~K}$. As a result of the heating the $\mathrm{C}_{4} \mathrm{H}_{6} \mathrm{O}_{4}$ was vaporized from the "boat" and the vapor condensed on the ATD particles in the cooler section downstream of the heated tube. The third tube (C) contained a "boat" filled with $\mathrm{H}_{2} \mathrm{SO}_{4}$. This tube was surrounded by a water jacket the temperature of which was controlled by a thermostat (HAAKE C25P, HAAKE GmbH, Karlsruhe, Germany). Two temperature values were used during the experiments $\left(50^{\circ} \mathrm{C}\right.$ and $\left.70^{\circ} \mathrm{C}\right)$ resulting in two different amounts of $\mathrm{H}_{2} \mathrm{SO}_{4}$ on the particles. The temperature stability was $\pm 0.1 \mathrm{~K}$. To generate the $\left(\mathrm{NH}_{4}\right)_{2} \mathrm{SO}_{4}$ coating, the ATD particles were first led through the $\mathrm{H}_{2} \mathrm{SO}_{4}$ tube heated to $70^{\circ} \mathrm{C}$. Then, the particles were passed over a water bath. The aerosol here was humidified to dew-point temperature similar to the laboratory temperature of about $25^{\circ} \mathrm{C}$. Then, ammonia gas was added. The neutralization of the particulate $\mathrm{H}_{2} \mathrm{SO}_{4}$ by the ammonia took place in a three meter long reaction tube. After that the aerosol flow was dried using a diffusion dryer.

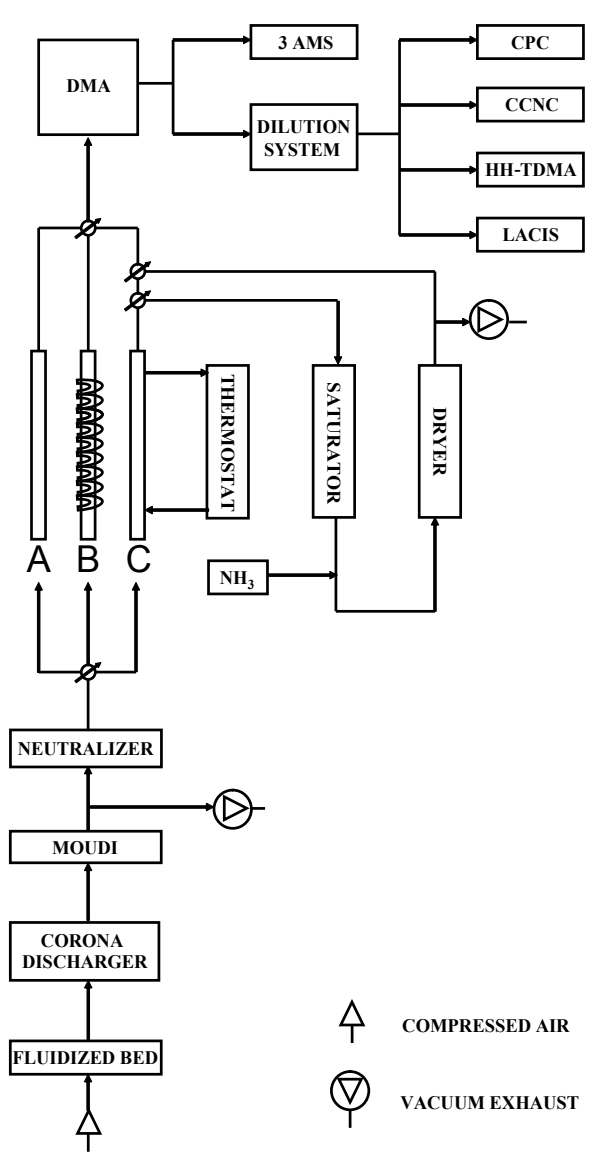

Fig. 1. Sketch of the generation, coating and size selection of the particles. Also included are the different instruments which measured during FROST.

Downstream of the coating device, a DMA (Differential Mobility Analyzer; Knutson and Whitby (1975); type "Vienna Medium") was used to select a quasi-monodisperse particle size fraction. For the freezing experiments, particles with a mobility diameter of $300 \mathrm{~nm}$ were selected. This particle size was chosen because in the atmosphere the absolute majority of IN is generally found below one micrometer (Mertes et al., 2007). To avoid a major contribution of doubly-charged particles, also care was taken that the maximum of the generated particle size distribution was at a size smaller than the selected particle size, i.e., the maximum appeared at about $200 \mathrm{~nm}$. For the selected particles, the coatings amounted to masses that were equivalent to a coating thickness in the range of $1-10 \mathrm{~nm}$ (Wex et al., 2010). Therefore, the coating masses were similar to amounts of soluble material that can be acquired by atmospheric particles due to cloud processing (Mertes et al., 2005; Yuskiewicz et al., 1999).

Downstream of the DMA the aerosol flow was split by a flow divider with one fraction $\left(0.661 \mathrm{~min}^{-1}\right)$ being directly fed to three Aerosol Mass Spectrometers (AMS, from IFT, 


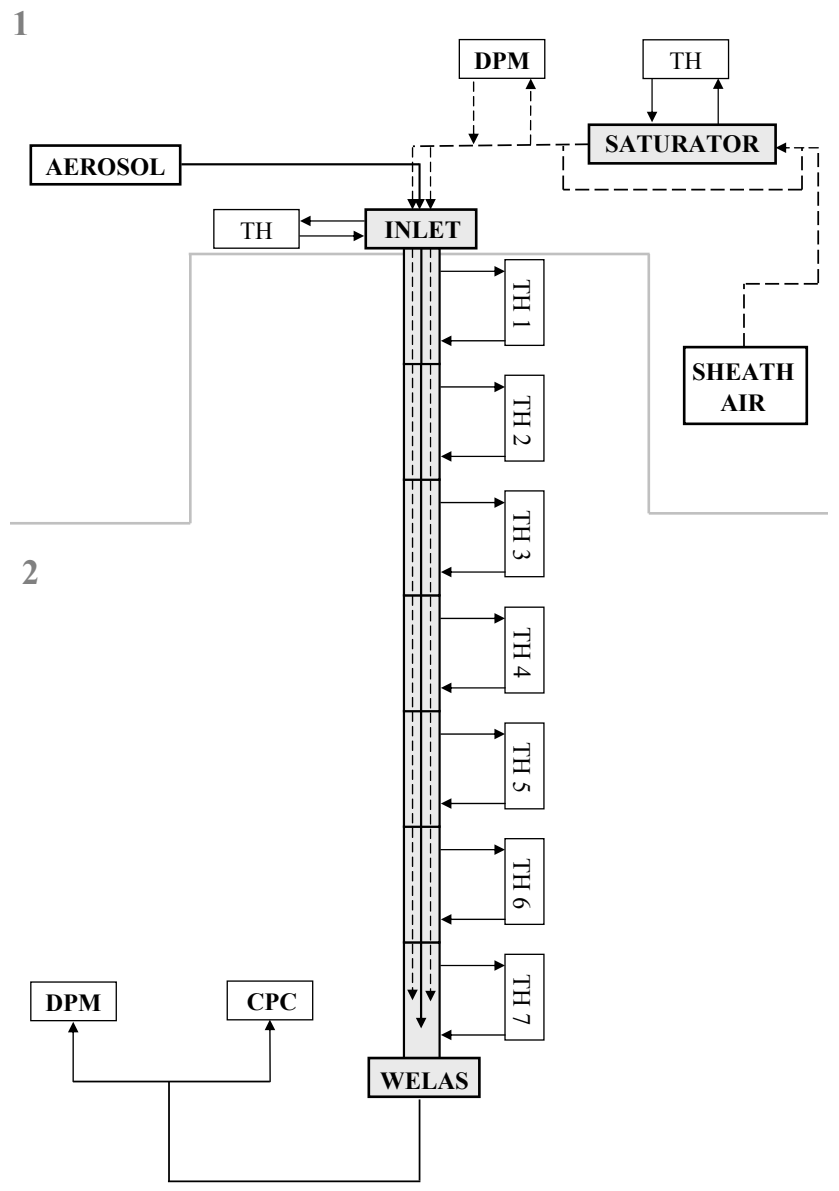

Fig. 2. Setup of particle conditioning (1) and LACIS laminar flow tube (2).

Research Center Jülich, Germany and Max Planck Institute for Chemistry, Mainz, Germany, Reitz et al., 2010). The other fraction $\left(0.341 \mathrm{~min}^{-1}\right)$ was led to a dilution system where particle free air $\left(1.51 \mathrm{~min}^{-1}\right)$ was added. All flows were controlled by mass flow controllers (MKS 1179, MKS Instruments Deutschland GmbH, Munich, Germany) and checked on a daily basis with a bubble flow meter (Gilian ${ }^{\circledR}$ Gilibrator $^{\mathrm{TM}} 2$, Sensidyne Inc., Clearwater, Florida, USA). From here, the remaining instruments (Condensation Particle Counter (CPC, GRIMM 5.401, GRIMM Aerosol Technik GmbH \& Co. KG, Ainring, Germany); Cloud Condensation Nucleus Counter (CCNC, DMT, Boulder, Colorado, USA, Roberts and Nenes, 2005), High-Humidity Tandem Differential Mobility Analyzer (HH-TDMA, Hennig et al., 2005) and LACIS) were fed with the required flows. For LACIS measurements an aerosol flow of $0.081 \mathrm{~min}^{-1}$ was used.

\subsection{LACIS-measurement procedure and data evaluation}

During FROST, the first heterogenous freezing measurements at LACIS were performed. Therefore, a straightforward and simple measurement setup was used.

The aerosol flow entered LACIS (Fig. 2) with a dew-point temperature of about $233 \mathrm{~K}$. A certain fraction of particle free sheath air flow was humidified by a saturator (Perma Pure PH-30T- 24KS, Perma Pure LLC, Toms River, New Jersey, USA) and subsequently mixed with a dry particle free air flow resulting in a dew-point temperature of $266.15 \mathrm{~K}$. This dew-point temperature was monitored using a dewpoint mirror (DPM, Dew Prime I-S2, Edge Tech, Milford, Massachusetts, USA) featuring an accuracy of $\pm 0.10 \mathrm{~K}$.

The aerosol and sheath air flows were combined in the inlet section of LACIS. The aerosol was confined by the sheath air to a narrow beam (about $2 \mathrm{~mm}$ in diameter) at the center axis of LACIS. The volume flow rates of sheath air and aerosol flow were chosen such that both flows entered LACIS in an isokinetic fashion with a velocity of about $0.4 \mathrm{~m} \mathrm{~s}^{-1}$.

LACIS is a laminar flow tube with a diameter of $15 \mathrm{~mm}$. During our experiments, we used a total length of $7 \mathrm{~m}$, made up of seven $1 \mathrm{~m}$ tubes, each surrounded by a thermostated water-jacket (thermostats 1 to 5: JULABO FP50, JULABO Labortechnik GmbH, Seelbach, Germany; thermostats 6 to 7: JULABO LH85) so that the temperature of each section could be controlled separately (Fig. 2).

For the detection of the particles at the outlet of LACIS, a white light aerosol spectrometer (WELAS ${ }^{\circledR} 1000$, PALAS $^{\circledR}$, Karlsruhe, Germany) was used. Downstream of WELAS ${ }^{\circledR}$, the particle number concentration was measured by means of a CPC (TSI 3010, TSI Inc., St. Paul, Minnesota, USA). The outlet dew-point temperature was monitored using a DPM (MBW 973, MBW Calibration Ltd., Wettingen, Switzerland).

During FROST, the inlet temperature and the wall temperature of the first LACIS section were set to $293.15 \mathrm{~K}$. The wall temperatures of section two to five were set to 273.15 K. During the experiments, which were performed under atmospheric pressure conditions, only the temperatures of Sects. 6 and 7 were adjusted in a range where freezing was observable. Here, two different measurement procedures were carried out. In the first case only Sect. 7 was cooled down to temperature values between $233.15 \mathrm{~K}$ and $239.15 \mathrm{~K}$ and Sect. 6 was kept at $273.15 \mathrm{~K}$ (one-section measurement). In the second case Sects. 6 and 7 were cooled down to the same temperature, ranging between $233.15 \mathrm{~K}$ and $239.15 \mathrm{~K}$ (two-section measurement). The accuracy of the adjusted temperatures for all temperatures in the range from $233.15 \mathrm{~K}$ to $239.15 \mathrm{~K}$ was $\pm 0.60 \mathrm{~K}$. For wall temperatures below $273.15 \mathrm{~K}$, the corresponding inner tube walls were covered with ice by cooling the respective tube(s) down to $233.15 \mathrm{~K}$ for 5 to $10 \mathrm{~min}$ prior to the measurement start. 
This procedure was necessary to ensure well-defined and reproducible wall boundary conditions.

The inlet conditions in combination with the wall temperatures determine the temperature and saturation profiles inside LACIS. As mentioned above, the inlet conditions and the wall temperature of the first five sections were fixed and only the temperatures of Sects. 6 and 7 were varied. Therefore, the relevant microphysical processes as particle activation, growth and freezing of the droplets do occur in the last two sections and are controlled by the boundary conditions in these sections (Hartmann et al., 2010). In Fig. 3, model simulations of the axial temperature profile the particles are exposed to, as well as the droplet growth behavior inside the last two sections are presented for different wall temperatures $(233.15 \mathrm{~K}, 238.15 \mathrm{~K}$ and $239.15 \mathrm{~K})$. The simulations were performed using the Computational Fluid Dynamics (CFD) code FLUENT 6 (FLUENT, 2001) together with the Fine Particle Model (FPM) (Particle Dynamics, 2005). The boundary conditions for the simulations were equal to the experimental ones assuming the inner tube walls of Sects. 6 and 7 to be covered with ice.

Considering the axial temperature profiles (Fig. 3), the temperature decreases steeply within the first freezing section and reaches the adjusted wall temperature in the second freezing section. Note that the temperature is almost constant within the second freezing section. Due to density related flow velocity changes, the residence time inside the tube increases slightly with decreasing wall temperature. In the second freezing section the residence time is nearly constant (about $1.6 \mathrm{~s})$.

The trajectories in Fig. 3 show at which temperatures the water droplets are formed and which temperatures they experience during their growth and evaporation process while traveling along the LACIS axis (from right to left). With the temperature decreasing, particles/droplets are activated (after about $0.5 \mathrm{~s}$ at $T_{\text {axis }}$ laying between $257 \mathrm{~K}$ and $260 \mathrm{~K}$ ) and grow dynamically, roughly until reaching the end of the first freezing section (marked with the black squares). Further downstream, droplets start to evaporate due to WegenerBergeron-Findeisen effect (Findeisen, 1938) because the particle environment becomes subsaturated with respect to liquid water but is still ice supersaturated. For a wall temperature of $239.15 \mathrm{~K}$ droplets evaporate, become deactivated and reach their equilibrium diameter towards the end of the second freezing section (marked with an open square). For a wall temperature of $238.15 \mathrm{~K}$, the behavior is somewhat similar, but the droplets survive, although they shrink significantly. For a wall temperature of $233.15 \mathrm{~K}$, droplets only shrink to a small extend and would leave LACIS as large activated droplets.

From these simulations it becomes obvious that in LACIS different ice nucleation mechanisms, i.e., immersion and evaporation freezing, and deposition nucleation could occur. Since experiments are performed for temperatures below $235 \mathrm{~K}$, also homogeneous freezing would be possible.

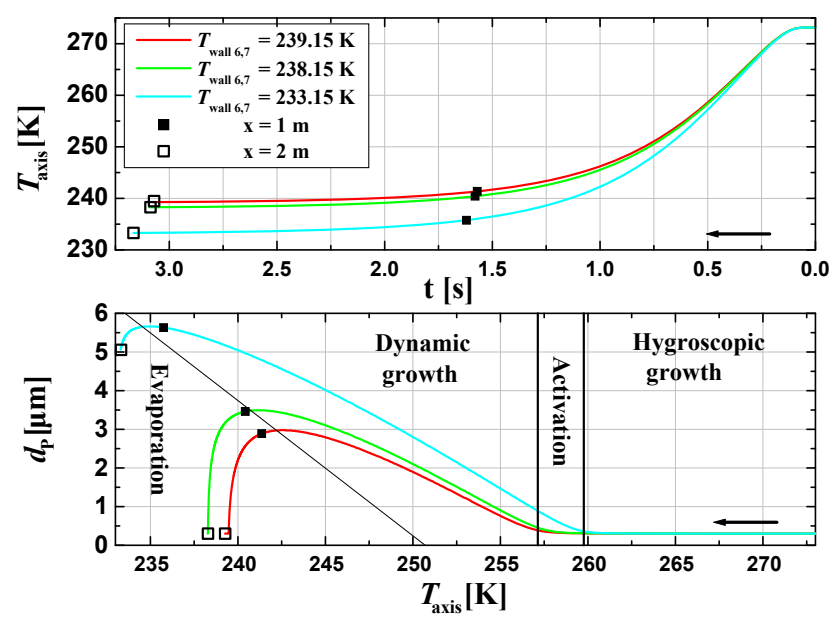

Fig. 3. Both panels: FLUENT/FPM model simulations for three different wall temperatures $(233.15 \mathrm{~K}, 238.15 \mathrm{~K}$ and $239.15 \mathrm{~K})$. The black and the open square represent the end of the first and second freezing section. The curves are traced from right to left as particles cool monotonically while moving along the axis of the LACIS flow tube. Upper panel: Simulations of the axial temperature profile the particle beam is exposed to as function of residence time inside LACIS. Lower Panel: Simulations of the droplet growth behavior inside the two freezing sections. $T_{\text {axis }}$ is the temperature which the particles experience in the particle beam.

An analysis concerning the actual freezing modes observed in LACIS during FROST will be given in Sect. 4. For more detailed information concerning the thermodynamic conditions and profiles for different settings at LACIS please refer to Hartmann et al. (2010).

The main goal of this study was to obtain ice fractions, whereas knowing the correct size of the ice particles with large accuracy is less relevant. Under these circumstances $\mathrm{WELAS}^{\circledR}$ was an adequate device to meet the requirements, with two disadvantages that, however, can be overcome.

Firstly, the distinction between seed particles (coated or uncoated ATD particles), supercooled water droplets and ice crystals is not straightforward. However, the optical signal which originates from the seed particles is smaller than signals resulting from the droplets/ice crystals and is clearly distinguishable from them. Under the given conditions inside LACIS, the spherical droplets activate and grow (or evaporate) to similar sizes resulting in a narrow size distribution. In contrast, the growth of the ice crystals results in nonspherical shapes, and leads to optically much broader size distributions in comparison to the droplets. This behavior is utilized to distinguish between droplets and ice particles.

Secondly, the counting efficiency of WELAS ${ }^{\circledR}$ is particle size dependent. The counting efficiency is close to zero for the particles at the lower detection limit (about $300 \mathrm{~nm}$ for water droplets) and 1 for particles above $1 \mu \mathrm{m}$ (this size corresponds to a WELAS ${ }^{\circledR}$ size channel $>80$ ). In the transition 


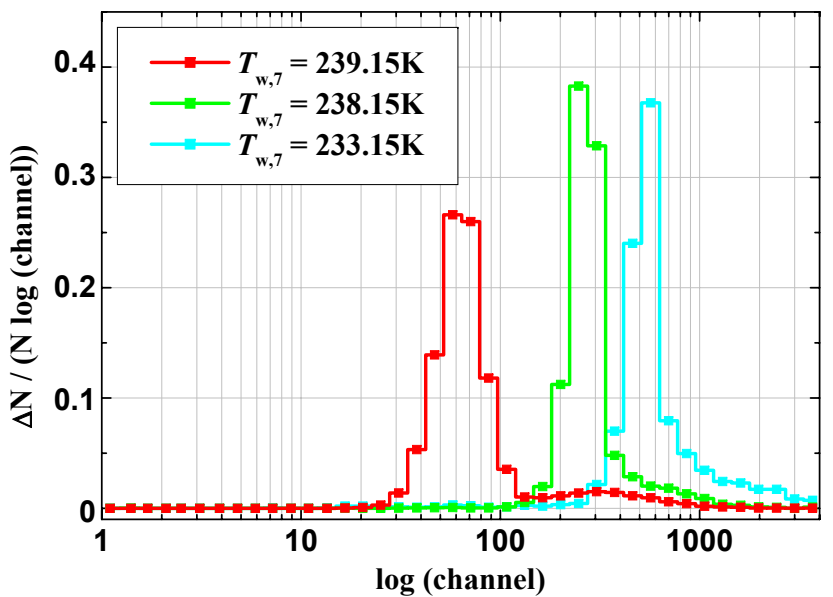

Fig. 4. Measured size distributions for one-section measurements at three different wall temperatures. The normalized number is plotted versus the logarithm of WELAS ${ }^{\circledR}$ size channel. The narrow modes are caused by supercooled liquid water droplets, while the tails originate from ice crystals.

range the counting efficiency is a function of the scattering signal amplitude and should be corrected if accurate measurements of particle number concentrations are required. During the FROST experiment, analyzed particles occupied two clearly separated size ranges: small seed particles (coated and uncoated ATD particles detected at WELAS ${ }^{\circledR}$ size channels $<80$ ), and large water droplets and ice crystals with sizes larger than $1 \mu \mathrm{m}$ (detected at WELAS ${ }^{\circledR}$ size channels >80). This allowed the application of a steplike correction function, neglecting the transition region between the small and large particles. The necessary correction was obtained by simultaneously measuring the number concentration of particles of known sizes with a CPC and WELAS ${ }^{\circledR}$. It also had to be considered that the dimension of the particle beam in LACIS is larger than the WELAS ${ }^{\circledR}$ optical measurement volume. To account for this, an experimentally determined correction factor $C_{\mathrm{MV}}=0.42 \pm 0.05$ was determined from measurements of droplets with sizes clearly above $1 \mu \mathrm{m}$. The additional correction factor to obtain the number of small seed particles was found to be $C_{\text {seed }}=0.05 \pm 0.03$. The correction factor for the seed particles is valid for all particle types investigated during FROST.

In order to calculate the ice fraction $f_{\text {ice }}$ from a LACIS experiment, the number of ice crystals $N_{\mathrm{f}}$ has to be divided by the total number $N_{0}$ (see Eq. 6) wherein $N_{0}$ and $N_{\mathrm{f}}$ are obtained through:

$N_{0}=\frac{\frac{N_{\text {seed }}}{C_{\text {seed }}}+N_{\text {drop } / \text { ice }}}{C_{\mathrm{MV}}}, N_{\mathrm{f}}=\frac{N_{\text {ice }}}{C_{\mathrm{MV}}}$.

Here, $N_{\text {seed }}$ and $N_{\text {drop/ice }}$ represent the uncorrected number of small seed particles and the number of large water

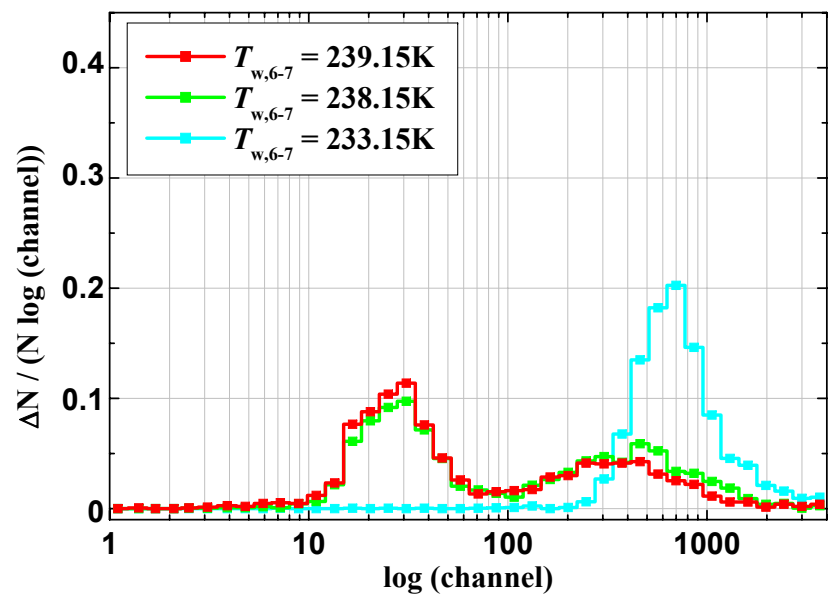

Fig. 5. Measured size distributions for two-section measurements at three different wall temperatures. The normalized number is plotted versus the logarithm of WELAS ${ }^{\circledR}$ size channel. The mode below channel 80 is the seed mode. The broad modes above channel 80 are ice crystal modes. In contrast to one-section measurement supercooled liquid droplets are absent.

droplets/ice crystals as obtained from the $\mathrm{WELAS}^{\circledR}$ measurement, respectively. All measured particles were corrected as described above. As a consistency check, during all measurements $N_{0}$ determined from Eq. (13) was compared to the number counted by the CPC (uncertainty of $\pm 5 \%$ ). Both numbers matched within measurement uncertainties for the different experiments done for this study.

In the following, results of a one- and a two-section measurement using pure ATD particles as IN are presented (Figs. 4 and 5). Two different particle modes appeared during a LACIS one-section measurement: supercooled water droplet mode and ice crystal mode. It can be seen in Fig. 4 that the water droplet and the ice crystal modes overlap, making a clear distinction between these modes difficult. Consequently, the ice fractions determined suffer from large uncertainties. Therefore, this kind of measurements was not used for quantifying ice fractions. Nevertheless, these measurements show, that first droplets are generated which then start to freeze. Therefore, the one-section measurements provide valuable insight into the freezing modes occurring inside LACIS (see next section).

In two-section measurements as depicted in Fig. 5, the supercooled droplets either freeze or evaporate due to the Wegener-Bergeron-Findeisen effect, caused by both the ice at the inner tube walls and the already frozen droplets. Therefore, the sharp droplet mode is absent and clearly distinguishable seed and ice crystal modes remain with only the respective number concentrations varying with changing wall temperatures. At the lowest temperature of $233.15 \mathrm{~K}$ only ice crystals were observed (see Fig. 5). These two-section measurements were used to determine ice fractions for different 


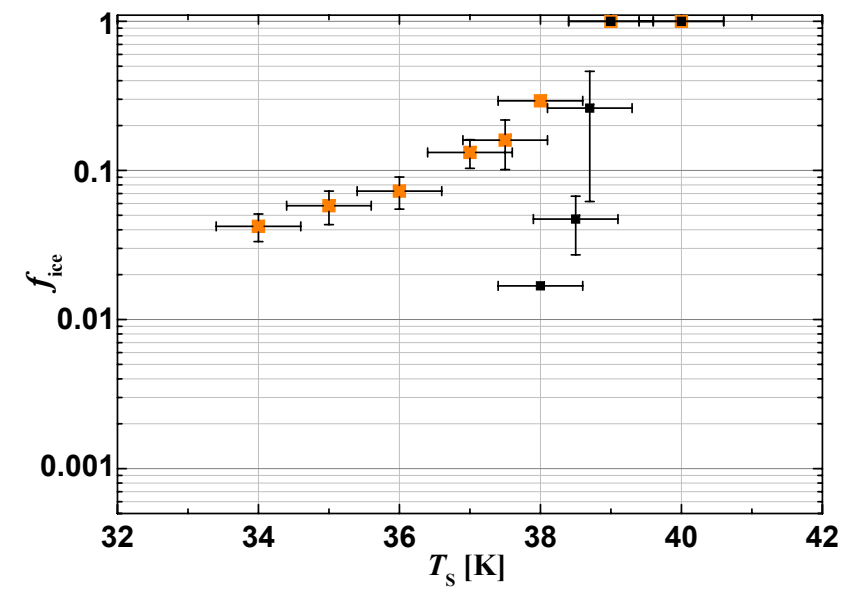

Fig. 6. Ice fraction $f_{\text {ice }}$ derived for pure ATD particles at different $T_{\mathrm{S}}$ (orange squares) and for homogeneous freezing of highly diluted ammonium sulfate droplets (black squares).

temperature values. A bimodal log-normal fit procedure was performed to separate seed and ice crystal mode and to determine the number of seed particles and ice crystals.

\section{Results}

Figure 6 presents $f_{\text {ice}}$, obtained for pure ATD particles as a function of supercooling temperature ranging from $34 \mathrm{~K}$ to $40 \mathrm{~K}$, where the supercooling temperature is defined as $T_{\mathrm{s}} \equiv T_{\circ}-T$, with $T$ corresponding to the adjusted wall temperature of the two freezing sections $T_{\mathrm{w}, 6-7}$.

As mentioned above, $f_{\text {ice }}$ were obtained from the twosection measurements, after correction of the WELAS ${ }^{\circledR}$ size dependent counting efficiency (Eq. 13). Each data point was measured at least three times (with 1000 to 10000 particles for each measurement) and the error bars represent the respective standard deviations.

Figure 6 shows that with increasing $T_{\mathrm{s}}, f_{\text {ice }}$ increases monotonically, reaching a value of 1 at $T_{\mathrm{s}}=39 \mathrm{~K}$, i.e., all droplets are frozen. Due to the temperature profile inside LACIS, each data point represents an integrated ice fraction from $T_{\circ}$ to $T_{\mathrm{S}}$ at the end of the tube.

The question arises, which freezing modes occur when running LACIS as described above. Since the measurements were performed for values of $T_{\mathrm{s}}$ up to $40 \mathrm{~K}$, homogeneous freezing is probable for the highest supercoolings. To verify this, homogeneous freezing of highly diluted ammonium sulfate solution droplets was studied. Homogeneous freezing was clearly detectable for $T_{\mathrm{s}} \geq 38 \mathrm{~K}$ (see Fig. 6). Therefore, heterogeneous and homogeneous freezing are not distinguishable for $T_{\mathrm{s}} \geq 38 \mathrm{~K}$. These data points will not be considered in the later analysis.

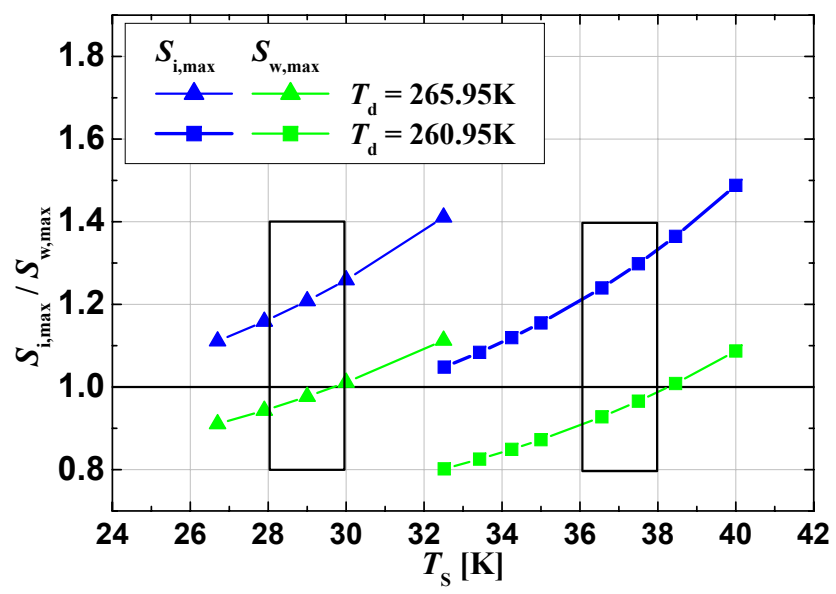

Fig. 7. FLUENT/FPM model simulations for LACIS adjustments to measure possible deposition nucleation. The maximum saturation ratios with respect to ice (blue) and liquid water (green) are plotted versus $T_{\mathrm{S}}$ for two different inlet dew-points $(265.95 \mathrm{~K}$ (triangle) and 260.95 K (square)). The black boxes represent the measurement region.

To test if deposition nucleation occurred inside the tube, specific two-section measurements were performed wherein LACIS was operated in the water subsaturated and ice supersaturated mode. These additional experiments were carried out for two different inlet dew-points $(265.95 \mathrm{~K}$ and $260.15 \mathrm{~K}$ ) to detect possible deposition nucleation in two different temperature intervals (from $T_{\mathrm{s}}=28 \mathrm{~K}$ to $30 \mathrm{~K}$ for dewpoint of $265.95 \mathrm{~K}$ and from $T_{\mathrm{s}}=36 \mathrm{~K}$ to $38 \mathrm{~K}$ for dew-point of $260.15 \mathrm{~K}$, see Fig. 7). For the lower $T_{\mathrm{s}}$ interval no deposition nucleation was observable. For the higher $T_{\mathrm{s}}$ interval deposition nucleation was detectable but the counted number of ice crystals was so low that deposition nucleation can be neglected for the FROST measurements.

Evaporation freezing could occur as the droplets generated in LACIS evaporate due to the Wegener-BergeronFindeisen effect. However, the one-section measurements clearly show that liquid droplets and ice crystals coexist. Because the droplet size distribution is narrow, the ice particles are most likely not formed by evaporation freezing (and also not through a condensation freezing process). In other words the ice formation observed must be due to the process of immersion freezing. In addition, the smooth ice fraction behavior determined from the two-section measurements for $T_{\mathrm{S}}$ between $34 \mathrm{~K}$ and $37.5 \mathrm{~K}$ is suggestive for the occurrence of a single heterogenous freezing mode, namely immersion freezing.

Finally, $f_{\text {ice }}$ values for all measured IN at different $T_{\mathrm{S}}$ are presented in Fig. 8. With increasing $T_{\mathrm{s}}, f_{\text {ice increases for }}$ all IN types, but in a different manner. Uncoated particles and those with $\mathrm{C}_{4} \mathrm{H}_{6} \mathrm{O}_{4}$ coatings or with small amounts of $\mathrm{H}_{2} \mathrm{SO}_{4}$ (1) start to act as IN at lower $T_{\mathrm{S}}$ compared to particles 


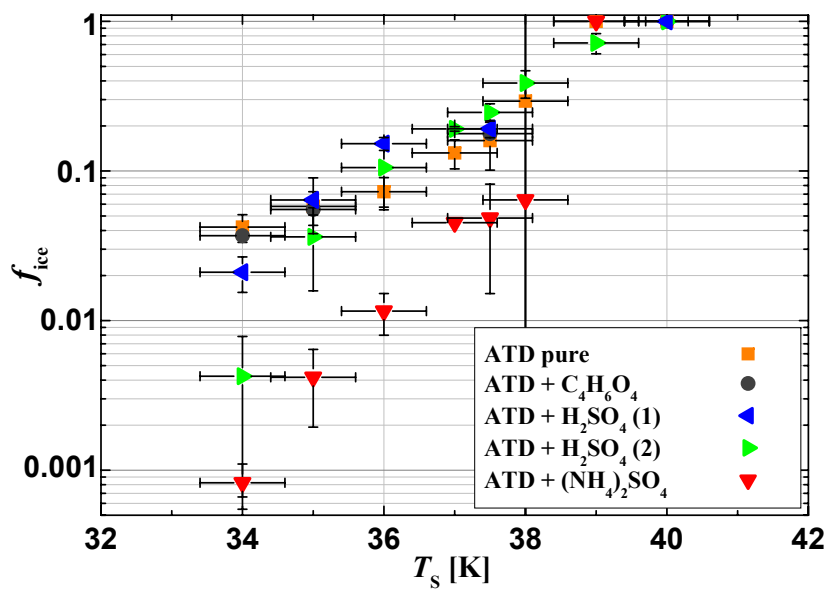

Fig. 8. Immersion freezing behavior of all types of examined particles. Each data point was measured at least three times (with 1000 to 10000 particles for each measurement) and the error bars represent the respective standard deviations. The line at $T_{\mathrm{S}}=38 \mathrm{~K}$ separates the heterogeneous (on the left) and homogeneous (on the right) freezing modes.

Table 1. Parameters $a$ and $f_{\text {het }}$ of the CNT type nucleation rate expression for the immersion freezing of supercooled water droplets containing different types of IN.

\begin{tabular}{lll}
\hline Particle Type & $a\left[\mathrm{~s}^{-1}\right]$ & $f_{\text {het }}$ \\
\hline ATD & $1.31 \mathrm{E}+00$ & $4.51 \mathrm{E}-02$ \\
ATD $+\mathrm{C}_{4} \mathrm{H}_{6} \mathrm{O}_{4}$ & $8.46 \mathrm{E}+00$ & $6.83 \mathrm{E}-02$ \\
$\mathrm{ATD}+\mathrm{H}_{2} \mathrm{SO}_{4}(1)$ & $1.57 \mathrm{E}+01$ & $7.79 \mathrm{E}-02$ \\
$\mathrm{ATD}+\mathrm{H}_{2} \mathrm{SO}_{4}(2)$ & $5.71 \mathrm{E}+02$ & $1.35 \mathrm{E}-01$ \\
ATD $+\left(\mathrm{NH}_{4}\right)_{2} \mathrm{SO}_{4}$ & $1.31 \mathrm{E}+02$ & $1.40 \mathrm{E}-01$ \\
\hline
\end{tabular}

with larger amounts $\mathrm{H}_{2} \mathrm{SO}_{4}$ (2) or with $\left(\mathrm{NH}_{4}\right)_{2} \mathrm{SO}_{4}$ coatings. For $T_{\mathrm{s}}=34 \mathrm{~K}$, pure ATD particles feature the largest IN capability. For $T_{\mathrm{s}} \geq 35 \mathrm{~K}$, pure ATD particles and those coated with $\mathrm{C}_{4} \mathrm{H}_{6} \mathrm{O}_{4}$, small and large amounts of $\mathrm{H}_{2} \mathrm{SO}_{4}$ seem to have a similar IN ability while particles coated with $\left(\mathrm{NH}_{4}\right)_{2} \mathrm{SO}_{4}$ are the most ineffective IN for the whole temperature range investigated.

\section{Discussion}

The question remains, what factors cause the difference in the freezing behavior in the absence or presence of different coatings. For the investigated temperature range the droplets inside LACIS are activated and reach diameters larger than $1 \mu \mathrm{m}$ before freezing occurs. Considering the coating amounts it follows that the water activity $a_{\mathrm{w}}$ of the supercooled droplets is about 1 , i.e., the droplet solution is highly diluted. Consequently, a freezing point suppression, found e.g., by Hung et al. (2003) and Zobrist et al. (2008)

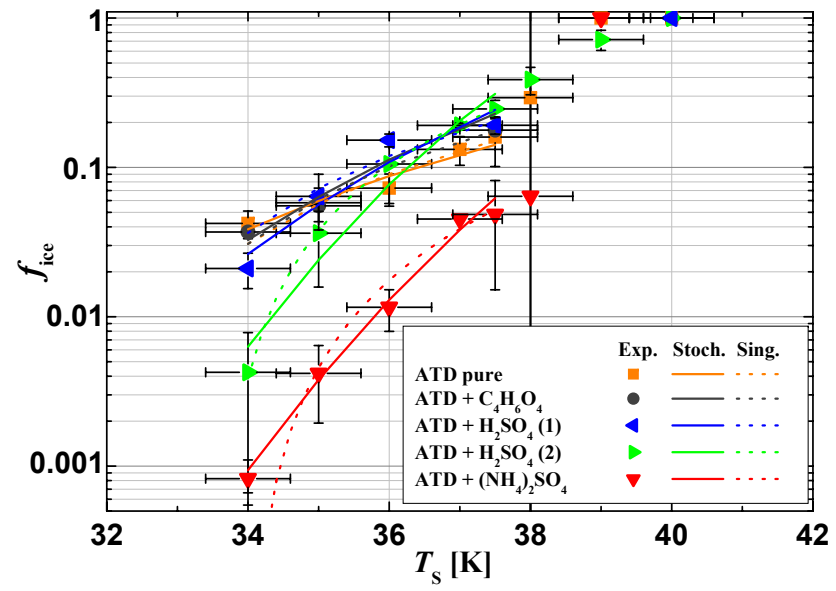

Fig. 9. Immersion freezing behavior of all examined types of particles. The determined $f_{\text {ice }}$ and the parameterization curves of both approaches are plotted (see Eqs. 8 and 11 together with 12). The line at $T_{\mathrm{S}}=38 \mathrm{~K}$ separates the heterogeneous (on the left) and homogeneous (on the right) freezing modes.

for various aqueous solution droplets with immersed mineral dust particles, could not be observed during FROST.

As the observed freezing behavior cannot be explained by solution effects, it is straightforward to assume that it is due to changes in the surface properties of the IN caused by the different coatings. To test this hypothesis, we applied the parameterizations described in Sect. 2 in the following way:

- Fit Eqs. (8) and (11)/(12) to the experimental data by adjusting the respective free parameters.

- Identify systematic trends in the determined parameters as a function of coating.

- Relate the trends observed to the physical meaning behind the respective parameters.

By comparing the results of the stochastic and the singular approach, with the measurements we may learn which of the two approaches is more suitable in explaining the immersion freezing process investigated.

First, the simplified CNT parameterization assuming the stochastic process (Eq. 8) was applied and the parameters $a$ and $f_{\text {het }}$ were determined for all types of IN studies. This parameterization is valid for the investigated temperature regime: $34 \mathrm{~K} \leq T_{\mathrm{S}}<38 \mathrm{~K}$. We repeat here, that the underlying assumption for the stochastic approach is that the major part of ice is formed in the second freezing section where the supercooling temperature reaches its highest value and is almost constant and where, therefore, $j_{\text {het }}$ is almost constant. This assumption is reasonable because the nucleation rate coefficient increases rapidly with increasing supercooling temperature. The residence time within the last freezing 


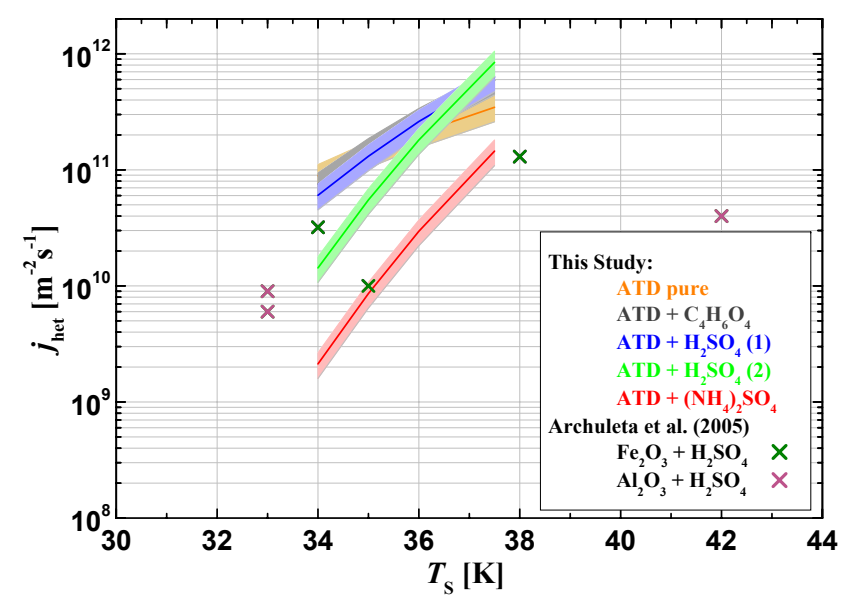

Fig. 10. Nucleation rates $j_{\text {het }}$ for all types of particles. For the determination of $j_{\text {het }}$, the values for $a$ and $f_{\text {het }}$ are inserted into Eq. (4) and all types of IN are assumed to be spherical with a volume equivalent diameter of $300 \mathrm{~nm}$. The crosses represent nucleation rates for sulfuric acid coated iron and aluminium oxide particles determined by Archuleta et al. (2005).

section is about $1.6 \mathrm{~s}$. The determined parameters are presented in Table 1 and the corresponding curves are plotted in Fig. 9. Inserting the determined values for $a$ and $f_{\text {het }}$ into Eq. (4) and assuming that all types of particles are nearly spherical (volume equivalent diameter of $300 \mathrm{~nm}$ ) with a uniform non-porous surface area, the corresponding nucleation rate coefficients can be calculated (see Fig. 10). Note that the ice nucleation efficiency of identically treated particles is assumed to be equal.

The curves of the nucleation rate coefficients in Fig. 10 reflect the ice nucleation potential of the particles. E.g., for $T_{\mathrm{s}} \geq 35 \mathrm{~K}$ the nucleation rate coefficient for $\left(\mathrm{NH}_{4}\right)_{2} \mathrm{SO}_{4}$ coated particles is about one order of magnitude lower compared to the other coated and uncoated particles, which exhibit similar nucleation rate coefficients within the uncertainties.

It is obvious from Table 1 that both parameters, $a$ and $f_{\text {het }}$, change for the different types of IN. The factor $f_{\text {het }}$ is smallest for pure ATD particles and highest for ATD particles coated with $\left(\mathrm{NH}_{4}\right)_{2} \mathrm{SO}_{4}$. That means that the energy barrier that has to be overcome to form a critical ice embryo on the particle surface, is lowest for pure ATD particles and highest for ATD particles coated with $\left(\mathrm{NH}_{4}\right)_{2} \mathrm{SO}_{4}$. This suggests that surface properties have been altered, or, in the context of CNT, that the interfacial free energy, or contact angle, has changed. It is plausible, for example, that the exposure of the sulfuric acid to water vapor, which occurs during the addition of ammonia to form $\left(\mathrm{NH}_{4}\right)_{2} \mathrm{SO}_{4}$, accelerates the reaction of sulfuric acid with the mineral dust, thereby leading to the greatest reduction in ice nucleating efficiency (Lasaga, 1995).

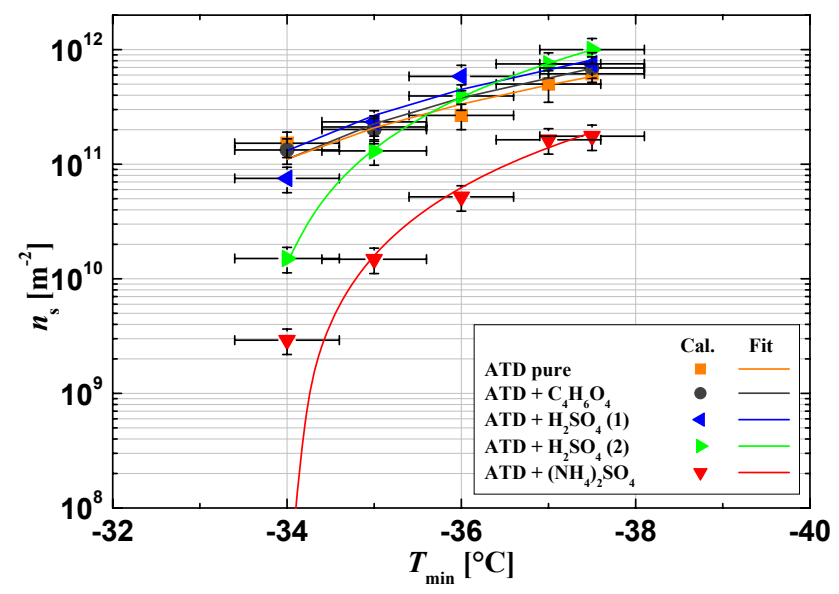

Fig. 11. Derived values for $n_{\mathrm{S}}(T)$ from the measurements (using Eq. 11) as well as curves resulting from parameterization (see Eq. 12) as function of temperature $\left[{ }^{\circ} \mathrm{C}\right]$.

Concerning parameter $a$, the lowest value is also obtained for pure ATD particles and the highest value for ATD coated with large amounts of $\mathrm{H}_{2} \mathrm{SO}_{4}$. Overall, the nucleation rate decreases as $a$ increases. Since $a$ includes information about total particle surface and kinetic effects, the increase can be interpreted as an increased surface area per particle, or as an increase in the rate at which molecules can be transferred from the liquid to ice. Since both values, $a$ and $f_{\text {het }}$, change in comparable manner, but with an opposite tendency compared to nucleation rate coefficient, it appears that the kinetic/surface term $(a)$ increases due to the coating but it is overcompensated by the thermodynamic term $\left(f_{\text {het }}\right)$. Consequently, the thermodynamic term seems to be most dominant for the change in immersion freezing behavior resulting from the coating processes. However, we have to be cautious not to over interpret these results because of the lack of knowledge of how the surface area itself is changing, and how uniform the surface properties are across the aerosol distribution.

Archuleta et al. (2005) also applied the stochastic hypothesis to determine nucleation rate coefficients for size segregated aluminum oxide and iron oxide particles (these substances are also components of the investigated ATD particles) which were treated with sulfuric acid. Their coefficients show a similar increase with increasing supercooling and have values comparable to our results (see Fig. 10). These rate coefficients, given for $a_{\mathrm{w}}=1$, are based on extrapolated intercepts from Continuous-Flow Ice-thermal Diffusion Chamber studies. For details please refer to Archuleta et al. (2005).

For data interpretation in terms of the singular hypothesis a parameterization for $n_{\mathrm{S}}(T)$ similar to that introduced by Connolly et al. (2009) was applied. It was also assumed that all particles types are nearly spherical with a volume 
Table 2. Parameters $\alpha_{1}$ and $\alpha_{2}$ for the parameterization of $n_{\mathrm{S}}(T)$ for the immersion freezing of supercooled water droplets containing different types of IN.

\begin{tabular}{lll}
\hline Particle Type & $\alpha_{1}\left[m^{-2 \circ} \mathrm{C}^{-2}\right]$ & $\alpha_{2}\left[{ }^{\circ} \mathrm{C}\right]$ \\
\hline ATD & $1.50925 \mathrm{E}+10$ & 31.29 \\
ATD $+\mathrm{C}_{4} \mathrm{H}_{6} \mathrm{O}_{4}$ & $2.01066 \mathrm{E}+10$ & 31.66 \\
ATD $+\mathrm{H}_{2} \mathrm{SO}_{4}(1)$ & $2.37200 \mathrm{E}+10$ & 31.65 \\
ATD $+\mathrm{H}_{2} \mathrm{SO}_{4}(2)$ & $6.32827 \mathrm{E}+10$ & 33.54 \\
ATD $+\left(\mathrm{NH}_{4}\right)_{2} \mathrm{SO}_{4}$ & $1.52053 \mathrm{E}+10$ & 33.97 \\
\hline
\end{tabular}

equivalent diameter of $300 \mathrm{~nm}$. Equation (11) was applied to derive $n_{\mathrm{S}}(T)$ directly from the measured ice fractions (see Fig. 11). For the determination of the fit parameters $\alpha_{1}$ and $\alpha_{2}$ (see Table 2), Eq. (12) was used by fitting the measurement based values for $n_{\mathrm{S}}(T)$. The resulting calculated curves for $n_{\mathrm{s}}(T)$ using the determined fit parameters are presented in Fig 11, too. The corresponding curves fitting the ice fractions are plotted in Fig. 9. These curves represent the fraction of ice active particles as function of $T$. Good agreement can be found between the fitted curves and the derived values for $n_{\mathrm{S}}(T)$ apart from the $\left(\mathrm{NH}_{4}\right)_{2} \mathrm{SO}_{4}$ coated particles. Here, the derived value for $n_{\mathrm{S}}(T)$ is under-predicted by the parametrization for $T_{\mathrm{S}}<35 \mathrm{~K}$.

For all particle types, $n_{\mathrm{S}}(T)$ increases with decreasing temperature but in different manner. The influence of the coatings on the active site density is clearly visible. For example, the values of $n_{\mathrm{s}}(T)$ for $\left(\mathrm{NH}_{4}\right)_{2} \mathrm{SO}_{4}$ coated ones are about one order of magnitude lower than values for pure ATD over the whole investigated temperature range. This behavior is also reflected by the parameter $\alpha_{2}$ which increases due to the coatings, i.e., the highest characteristic temperature $T_{\mathrm{c}}=-\alpha_{2}$ at which freezing starts to occur decreases due to the coating procedure. This suggests that surface properties have been altered, or, in the context of singular hypothesis, ice active sites on the particle surface are blocked, changed or destroyed due to the coating procedure. In order to examine the accurateness of the determined parameters $\alpha_{1}$ and $\alpha_{2}$, measurements at higher temperatures have to be performed.

To briefly summarize, the expressions from the stochastic and singular approaches can be fit with reasonable confidence to the experimentally determined results. Interpretation of the fitting parameters from both expressions is consistent with the notion that coating of the particles leads to a modification of the particle surface, thereby influencing nucleation efficiency. More strenuous tests, including different aerosol types and temperature range, and especially variations in exposure time (nucleation time), are needed in order to clearly favor one interpretation over the other.

\section{Conclusions}

During the measurement campaign FROST, LACIS was used to investigate the ability of size-segregated, coated and uncoated mineral dust particles to act as IN in the immersion freezing mode. These were the first measurements of heterogenous freezing performed with LACIS. For experiments Arizona Test Dust was used as a surrogate for mineral dust. The particles were also coated with various types of substances such as ammonium sulfate $\left(\left(\mathrm{NH}_{4}\right)_{2} \mathrm{SO}_{4}\right)$, sulfuric acid $\left(\mathrm{H}_{2} \mathrm{SO}_{4}\right.$, two different coating temperatures) and succinic acid $\left(\mathrm{C}_{4} \mathrm{H}_{6} \mathrm{O}_{4}\right)$. For the freezing experiments a quasimonodisperse particle size distribution with a mobility diameter of $300 \mathrm{~nm}$ was chosen. At LACIS, various temperature values between $233.15 \mathrm{~K}$ and $239.15 \mathrm{~K}$ were adjusted and corresponding ice fractions were determined. For the investigated temperature range the droplets inside LACIS are activated and highly diluted before freezing occurred. That means a freezing point suppression caused by the soluble coating material was not observed during FROST. Uncoated particles and those coated with $\mathrm{C}_{4} \mathrm{H}_{6} \mathrm{O}_{4}$ or small amounts of $\mathrm{H}_{2} \mathrm{SO}_{4}$ act as $\mathrm{IN}$ at higher temperatures compared to particles with larger amounts of $\mathrm{H}_{2} \mathrm{SO}_{4}$ or $\left(\mathrm{NH}_{4}\right)_{2} \mathrm{SO}_{4}$ coatings. The IN ability of the $\left(\mathrm{NH}_{4}\right)_{2} \mathrm{SO}_{4}$ coated particles is reduced by one order of magnitude in terms of the determined ice fractions compared to the uncoated particles. In general, particle treatment led to a decreased IN ability compared to the pure ATD particles. This suggests that chemical aging processes (i.e., through coatings) in the atmosphere will also lead to a decreased IN concentration for heterogeneous freezing processes. Indeed, these measurements would suggest that decreases in IN concentrations by up to one order of magnitude are realistic for the temperature range investigated.

Two theoretical approaches based on the stochastic and the singular hypothesis were tested separately to evaluate and parameterize the investigated freezing behavior of the different kinds of particles. Both parameterizations confirm the hypothesis that the coating of the particles leads to a modification of the particle surface influencing the nucleation efficiency. Using the CNT type nucleation rate expression in the stochastic approach, it is found that the energy barrier for freezing is increased. Furthermore, this parameterization suggests that the total particle surface and/or kinetic effects are also increased due to the coating procedure. But it appears that the kinetic/surface term increase is overcompensated by the thermodynamic term so that the thermodynamic term seems to be most dominant for the change in immersion freezing behavior resulting from coating processes. Using the singular approach, the surface modifications are manifested as a reduction in $n_{\mathrm{S}}(T)$ which is smallest for $\left(\mathrm{NH}_{4}\right)_{2} \mathrm{SO}_{4}$ coated particles in the temperature range investigated. That can be interpreted as a decrease in the number of ice active sites on the particle surface due to the coating procedure. 
In summary, both approaches, representing two individual fits, can be used to sufficiently describe the experimentally determined results within the measurement uncertainties. Therefore, we cannot clarify at the current state which approach correctly describes the investigated immersion freezing process. Further investigations have to be performed measuring at higher temperatures and varying particle size and nucleation times to quantify if one of the approaches or even a mixture of both has to be applied, e.g., following Marcolli et al. (2007) who could best describe their measurement results when using the singular hypothesis while keeping the stochastic concept of a nucleation rate.

Acknowledgements. The measurement campaign FROST was conducted within the Helmholtz Virtual Institute "Aerosol-Cloud Interactions" funded by the Helmholtz society. This work is part of a DFG project under contract HE 939/21-1. Additionally, the campaign was financially supported by the research project EUROCHAMP funded within the EC 6th Framework Program, Section "Support for Research Infrastructures - Integrated Infrastructure Initiative". R. A. Shaw acknowledges support from the Alexander von Humboldt Foundation during the time this research was carried out.

Edited by: T. Koop

\section{References}

Archuleta, C. M., DeMott, P. J., and Kreidenweis, S. M.: Ice nucleation by surrogates for atmospheric mineral dust and mineral dust/sulfate particles at cirrus temperatures, Atmos. Chem. Phys., 5, 2617-2634, 2005, http://www.atmos-chem-phys.net/5/2617/2005/.

Cantrell, W. and Heymsfield, A.: Production of ice in tropospheric clouds - A review, B. Am. Meteorol. Soc., 86(6), 795-807, 2005.

Connolly, P. J., Möhler, O., Field, P. R., Saathoff, H., Burgess, R., Wagner, R., Choularton, T., and Gallagher, M.: Studies of heterogeneous freezing by three different desert dust samples, Atmos. Chem. Phys., 9, 2805-2824, 2009,

http://www.atmos-chem-phys.net/9/2805/2009/.

Cziczo, D. J., Murphy, D. M., Hudson, P. K., and Thomson, D. S.: Single particle measurements of the chemical composition of cirrus ice residue during crystal-face, J. Geophys. Res.-Atmos., 109, D04201, doi:10.1029/2003JD004032, 2004.

Cziczo, D. J., Froyd, K. D., Gallavardin, S. J., Möhler, O., Benz, S., Saathoff, H., and Murphy, D. M.: Deactivation of ice nuclei due to atmospherically relevant surface coatings, Environ. Res. Lett., 4(4),2009.

DeMott, P. J., Cziczo, D. J., Prenni, A. J., Murphy, D. M., Kreidenweis, S. M., Thomson, D. S., Borys, R., and Rogers, D. C.: Measurements of the concentration and composition of nuclei for cirrus formation, Proc. Natl. Acad. Sci. USA, 100(25), 1465514660, 2003a.

DeMott, P. J., Sassen, K., Poellot, M. R., Baumgardner, D., Rogers, D. C., Brooks, S. D., Prenni, A. J., and Kreidenweis, S. M.: African dust aerosols as atmospheric ice nuclei, Geophys. Res. Lett., 30(14), 1732, doi:10.1029/2003GL017410, 2003b.
Durant, A. J. and Shaw, R. A.: Evaporation freezing by contact nucleation inside-out, Geophys. Res. Lett., 32, L20814, doi:10.1029/2005GL024175, 2005.

Field, P. R., Möhler, O., Connolly, P., Krämer, M., Cotton, R., Heymsfield, A. J., Saathoff, H., and Schnaiter, M.: Some ice nucleation characteristics of Asian and Saharan desert dust, Atmos. Chem. Phys., 6, 2991-3006, 2006,

http://www.atmos-chem-phys.net/6/2991/2006/.

Findeisen, W.: Die kolloidmeteorologischen Vorgänge bei der Niederschlagsbildung, Meteorologische Zeitung, 55, 121-133, 1938.

Fletcher, N. H.: Active sites and ice crystal nucleation, J. Atmos. Sci., 26(6), 1266-1271, 1969.

FLUENT: FLUENT 6 user's guide, FLUENT Inc., 2001.

Hartmann, S., Niedermeier, D., Shaw, R. A., Wex, H., and Stratmann, F.: Immersion freezing studies at the leipzig Aerosol Cloud Interaction Simulator, in preparation, 2010.

Hennig, T., Massling, A., Brechtel, F. J., and Wiedensohler, A.: A tandem DMA for highly temperature-stabilized hygroscopic particle growth measurements between $90 \%$ and $98 \%$ relative humidity, J. Aerosol Sci., 36, 1210-1223, 2005.

Hung, H. M., Malinowski, A., and Martin, S. T.: Kinetics of heterogeneous ice nucleation on the surfaces of mineral dust cores inserted into aqueous ammonium sulfate particles, J. Phys. Chem. A, 107(9), 1296-1306, 2003.

Kärcher, B. and Lohmann, U.: A parameterization of cirrus cloud formation: Heterogeneous freezing, J. Geophys. Res.-Atmos., 108, 4402, doi:10.1029/2002JD003220, 2003.

Knopf, D. A. and Koop, T.: Heterogeneous nucleation of ice on surrogates of mineral dust, J. Geophys. Res.-Atmos., 111, D12201, doi:10.1029/2005JD006894, 2006.

Knutson, E. O. and Whitby, K. T.: Aerosol classification by electric mobility: Apparatus, theory and applications, J. Aerosol Sci., 6, 443-451, 1975.

Langham, E. J. and Mason, B. J.: The heterogeneous and homogeneous nucleation of supercooled water, Proc. R. Soc. London Ser. A, 247(1251), 493-504, 1958.

Lasaga, A. C.: Fundamental approaches in describing mineral dissolution and precipitation rates, in: Chemical Weathering Rates of Silicate Minerals, volume 31 of Reviews in Mineralogy, pages 23-86. Mineralogical Society America, Washington, USA, 1995.

Lohmann, U.: Aerosol effects on clouds and climate, Space Sci. Rev., 125, 129-137, 2006.

Marcolli, C., Gedamke, S., Peter, T., and Zobrist, B.: Efficiency of immersion mode ice nucleation on surrogates of mineral dust, Atmos. Chem. Phys., 7, 5081-5091, 2007, http://www.atmos-chem-phys.net/7/5081/2007/.

Megahed, K.: The Impact of Mineral Dust Aerosol Particles on Cloud Formation, Dissertation, Rheinischen FriedrichWilhelms-Universität Bonn, 2007.

Mertes, S., Galgon, D., Schwirn, K., Nowak, A., Lehmann, K., Massling, A., Wiedensohler, A., and Wieprecht, W.: Evolution of particle concentration and size distribution observed upwind, inside and downwind hill cap clouds at connected flow conditions during FEBUKO, Atmos. Environ., 39, 4233-4245, 2005.

Mertes, S., Verheggen, B., Walter, S., Connolly, P., Ebert, M., Schneider, J., Bower, K. N., Cozic, J., Weinbruch, S., Baltensperger, U., and Weingartner, E.: Counterflow virtual impact or based collection of small ice particles in mixed-phase clouds 
for the physico-chemical characterization of tropospheric ice nuclei : Sampler description and first case study, Aerosol Sci. Technol., 48, 848-864, 2007.

Möhler, O., Field, P. R., Connolly, P., Benz, S., Saathoff, H., Schnaiter, M., Wagner, R., Cotton, R., Krämer, M., Mangold, A., and Heymsfield, A. J.: Efficiency of the deposition mode ice nucleation on mineral dust particles, Atmos. Chem. Phys., 6, 3007-3021, 2006, http://www.atmos-chem-phys.net/6/3007/2006/.

Particle Dynamics: FPM User's Guide, www.particle-dynamics.de, Particle Dynamics GmbH, Leipzig, Germany, 2005.

Prospero, J. M.: Long-term measurements of the transport of African mineral dust to the southeastern United States: Implications for regional air quality, J. Geophys. Res.-Atmos., 104(D13), 15917-15927, 1999.

Pruppacher, H. R. and Klett, J. D.: Microphysics of Clouds and Precipitation, Kluwer Academic Publishers, Dordrecht, The Netherlands, 1997.

Reitz, P., Schneider, J., Wex, H., Startmann, F., Niedermeier, D., Mildenberger, K., Covert, D., Spindler, C., Mentel, T. F., Poulain, L., and Borrmann, S.: Detection of thin coatings on refractory particles with an aerodyne aerosol mass spectrometer and implications for laboratory studies of hygroscopic growth, $\mathrm{CCN}$ and IN activation, in preparation, 2010.

Richardson, M. S., DeMott, P. J., Kreidenweis, S. M., Cziczo, D. J., Dunlea, E. J., Jimenez, J. L., Thomson, D. S., Ashbaugh, L. L., Borys, R. D., Westphal, D. L., Casuccio, G. S., and Lersch, T. L.: Measurements of heterogeneous ice nuclei in the western united states in springtime and their relation to aerosol characteristics, J. Geophys. Res.-Atmos., 112, D02209, doi:10.1029/2006JD007500, 2007.

Roberts, G. C. and Nenes, A.: A continuous-flow streamwise thermal-gradient $\mathrm{CCN}$ chamber for atmospheric measurements, Aerosol Sci. Technol., 39(3), 206-221, 2005.

Rogers, R. and Yau, M.: A Short Course in Cloud Physics, volume 3, Butterworth Heinemann-An imprint of Elsevier, third edition, 1996.

Sassen, K., DeMott, P. J., Prospero, J. M., and Poellot, M. R.: Saharan dust storms and indirect aerosol effects on clouds: Crystal-face results, Geophys. Res. Lett., 30, 1633, doi:10.1029/2003GL017371, 2003.
Seinfeld, J. and Pandis, S.: Atmospheric Chemistry and Physics From Air Pollution to Climate Change, Wiley-Interscience, 1998.

Shaw, R. A., Durant, A. J., and Mi, Y.: Heterogeneous surface crystallization observed in undercooled water, J. Phys. Chem. B, 109, 9865-9868, 2005.

Stratmann, F., Kiselev, A., Wurzler, S., Wendisch, M., Heintzenberg, J., Charlson, R. J., Diehl, K., Wex, H., and Schmidt, S.: Laboratory studies and numerical simulations of cloud droplet formation under realistic supersaturation conditions, J. Atmos. Oceanic Technol., 21(6), 876-887, 2004.

Vali, G.: Freezing rate due to heterogneous nucleation, J. Atmos. Sci., 51(13), 1843-1856, 1994.

Vali, G.: Repeatability and randomness in heterogeneous freezing nucleation, Atmos. Chem. Phys., 8, 5017-5031, 2008, http://www.atmos-chem-phys.net/8/5017/2008/.

Wex, H., Clauss, T., Covert, D., Hallbauer, E., Hartmann, S., Kiselev, A., Mentel, T. F., Mildenberger, K., Niedermeier, D., Poulain, L., Reitz, P., Schneider, J., Shaw, R., Spindler, C., and Stratmann, F.: Classifying coated and uncoated arizona test dust with respect to hygroscopic growth and activation, in preparation, 2010.

Yuskiewicz, B. A., Stratmann, F., Birmili, W., Wiedensohler, A., Swietlicki, E., Berg, O., and Zhou, J.: The effects of in-cloud mass production on atmospheric light scatter, Atmos. Res., 50, 265-288, 1999.

Zobrist, B., Koop, T., Luo, B. P., Marcolli, C., and Peter, T.: Heterogeneous ice nucleation rate coefficient of water droplets coated by a nonadecanol monolayer, J. Phys. Chem. C, 111(5), 21492155, 2007.

Zobrist, B., Marcolli, C., Peter, T., and Koop, T.: Heterogeneous ice nucleation in aqueous solutions: the role of water activity, $\mathrm{J}$. Phys. Chem. A, 112(17), 3965-3975, 2008.

Zuberi, B., Bertram, A. K., Cassa, C. A., Molina, L. T., and Molina, M. J.: Heterogeneous nucleation of ice in $\left(\mathrm{NH}_{4}\right)_{2} \mathrm{SO}_{4}-\mathrm{H}_{2} \mathrm{O}$ particles with mineral dust immersions, Geophys. Res. Lett., 29(10), 1504, doi:10.1029/2001GL014289, 2002. 